enable man to find a way to the control of those forces which the careless application of scientific discoveries and principles in the mechanical world has released. That simultaneously with increased efficiency of production there has been a perceptible though disproportionate increase in the general standard of living is at least of hopeful significance, and until national planning has been attempted on the lines Major Barley suggests, we remain without an answer to the questions whether it is possible to raise the standard of living and simultaneously to reduce unemployment to the required extent.

The concrete suggestion of a commission for individual industries under an expert National Advisory Economic Planning Department is similar to that since proposed by Capt. Macmillan under the Tariff Commission, and, like that, is essentially an attempt to determine whether, without radical changes in the nature of society, it may not be possible to organise on scientific lines the production, distribution, and exchange of goods so that the needs of the whole community may be adequately served.

\section{Plant Chemistry}

The Glycosides. By Dr. E. F. Armstrong and K. F. Armstrong. (Monographs on Biochemistry.) Pp. vii +123 . (London, New York and Toronto : Longmans, Green and Co., Ltd., 1931.) 12s. $6 d$. net.

THIS healthy bud from a vigorous parent 1 chronicles important advances in plant chemistry. A chapter in the senior author's earlier monograph, "The Simple Carbohydrates and the Glucosides", published in 1910, was called "The Natural and Synthetic Glucosides" and occupied 14 pages. This has now been expanded into the new volume, which fills 110 pages, exclusive of bibliography and indexes. The change of spelling from "glucosides" to "glycosides" is made in accordance with official practice, and is a recognition of the fact-apparently not realised in 1910that sugars other than glucose take part in forming these characteristic plant condensation products.

Several hundred of these substances have now been identified. Many are of a very complex nature, and their investigation is correspondingly difficult. The nature of the sugar itself has to be established; it is in most cases one or another of the modifications of glucose, though benzoyl-glucose, primeverose, vicianose, digitoxose, digitalose, and rhamnose have all been isolated from natural glycosides, as have several disaccharides and trisaccharides. The non-sugar part of the molecule may belong to any of an unusually wide range of compoundsphenols, coumarins, anthoxanthins, anthocyanins, isothiocyanates, and many others, including some the structure of which has not yet been worked out. The term "aglucone" for these constituents of glycosides seems a little illogical: surely it should have been "aglycone".

From the last two chapters of the book it is clear that the precise rôle of glycosides in plant physiology still awaits elucidation from the further intensive research that is certain to be undertaken, if only for the reason that a number have definite and recognised pharmacological action; among the better known of these are the glycosides of digitalis and strophanthus.

The volume is as well produced as others in this series, though there are some minor printing errors. Little attention has been paid to uniformity in the lay-out of the tables; Tables 1, 3, and 6 are arranged on one principle, Table 2 on another, Tables 4 and 5 on another, and neither Table 2 nor Table 5 has any column headings at all. Type and paper are adequate, but the luxurious effect of the transverse gold lettering replacing the old vertical black type on the spine is rather marred by its relative illegibility and bad centring.

A. L. Bacharach.

\section{Principles of Modern Physics}

Modern Physics : a General Survey of its Principles. By Rev. Theodor Wulf. Translated from the second German edition by C. J. Smith. Pp. $x i+469$. (London: Methuen and Co., Ltd., 1930.) 35s. net.

THE sixth-form scholar and the first-year 1 university student are in these days well catered for in the matter of textbooks of physics. To be sure, these in general conform to a standard pattern which lends itself to a grasp of detailed facts classified in a traditional and natural manner and to the requirements of examination tests. There has been a tendency, however, of late years to break away somewhat from this pattern, and the book under review constitutes a very notable departure indeed from accepted models. Assuming the "essential and final goal of Physics" to be " the derivation of phenomena on the basis of the internal structure of the smallest constituent particles of matter", the author states that his aim is to give a "co-ordinated account of the fundamental results of Physics ". In consequence, he collects in a first part the facts about the material world

$$
\text { No. 3268, Vor. 129] }
$$

